\title{
Optimizing Energy Harvesting System at Seismic Node: A Case of NNNSS Nodes
}

\author{
Dauda Duncan $^{1 *}$, Adamu Murtala Zungeru ${ }^{1}$, Mmoloki Mangwala ${ }^{1}$, Bakary Diarra ${ }^{2}$, Joseph Chuma $^{1}$, Bokani Mtengi ${ }^{1}$ \\ ${ }^{I}$ Department of Electrical, Computer and Telecommunications Engineering, Botswana International University of Science and \\ Technology, Private Bag 16, Palapye, Botswana. \\ ${ }^{2}$ Department of Electrical Engineering, Institute of Applied Sciences, University of Sciences, Techniques and Technologies of \\ Bamako (USTTB), Bamako, Mali.
}

ORCID: 0000-0003-2412-6559 (Adamu Murtala Zungeru)

\begin{abstract}
Seismic node is a relatively low duty acquisition electronic system that needs a reliable and continuous amount of electrical energy to perform optimally. Typically, the energy harvesting system at the node has low efficiency, fails frequently, and the node has gaps in its database. The key issues are losses across the employed conventional DC-DC converter employed. The study intends to address these losses by integrating the maximum power point tracking algorithm across the converter and optimally convert the harvested energy and deliver a simple, optimized, and cost-efficient system. The simulated results showed that the algorithm optimized the harvested energy. The performance in terms of power losses and outputs, as well as comparison with the existing power supply at the node, were simulated using PSIM. An additional $80 \%$ of power was delivered. The contributions of this study are: (1) identifying the constraints of energy harvesting system at NNNSS node and optimizing the constraints to delivering continuous power, and (2) implementing a simple and costeffective energy harvesting system at the remote seismic node.
\end{abstract}

Keywords: Algorithm, energy harvesting system, maximum power point tracking, node, photovoltaic, Seismic.

\section{INTRODUCTION}

Seismic activity is slowly becoming a prevalence event in Nigeria. In the past, it was barely uncharacteristic across the country [1] [2] [3]. Reliable and continuous seismic database creation is key to analyzing, interpreting, modelling, and predicting seismic events [4] [5]. The energy harvesting system is one of the significant factors that affect the continuous seismic database. Nigerian National Network of Seismographic Stations (NNNSS) uses a linear mode DC-DC converter, which is challenging and characterized by unjustified output power. A seismic node is a connection point within a seismic network that could be standalone, real-time, or near real-time. It detects, monitors, records, and processes seismic vibrations locally or remotely. The energy harvesting system converts unused ambient energy into electrical energy to power remote nodes, and energy storage is incorporated to complement its operations [6]. All energy harvesting system across NNNSS has a low efficiency below 10\%. This causes frequent failure of seismic node and unjustified cost during seismic instrumentation deployment, which is no different from a typical global seismic node [7].

Conventionally, a seismic node is energized by an energy harvesting system, which consists of a PV module, linear mode DC-DC converter to deliver fixed DC voltage, and lead-acid battery shown in Figure 1. During the peak periods of ambient irradiance levels, this mode of converter reduces the voltage to the level of the battery and load. Based on the current, voltage, and power relationships plotted from the baseline data of the case study in Figure 2 to Figure 4, there is perpetual wastage of generated power. Therefore, it is necessary to trade-off the voltage and current levels by the MPPT algorithm to deliver optimal values of $\mathrm{V}_{\mathrm{MAX}}$ and $\mathrm{P}_{\mathrm{MAX}}$, as shown in Figure 4. Usually, the inputs of the PV module, as shown in Figure 2, fluctuate in order to ensure an optimized power MPPT algorithm is inevitable. Meanwhile, the required electrical specifications of the case study are $12 \mathrm{~V}$ and $0.8 \mathrm{~A}$. The algorithm is developed to sit between the PV module and the DC-DC converter, as shown in Figure 5, to track the maximum power throughout its operations. The process whereby the algorithm controls an electronic circuit to track maximum point is known as Maximum Power Point Tracking (MPPT). The converter employed is based on buck converter topology in which harmonics and power losses are relatively lower than other switching mode converters. The output voltage ripples depend on the selected values of the capacitor and inductor, as well as the duty cycle and switching frequency of the MOSFET of the converter. Unlike buck converter, linear mode DC-DC converter produces little or no frequency noise. The voltage ripples were kept below $1 \%$, and that of current was below $10 \%$, which were simulated.

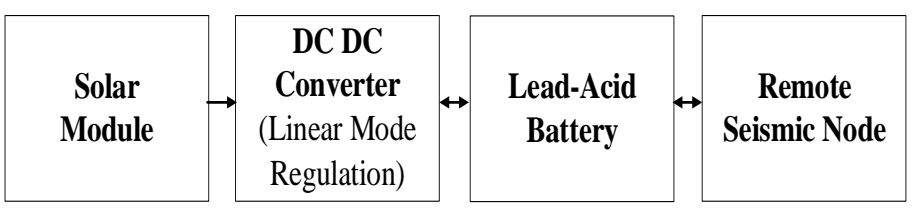

Figure 1. Block Diagram of a typical Energy Harvesting System at Seismic Node. 


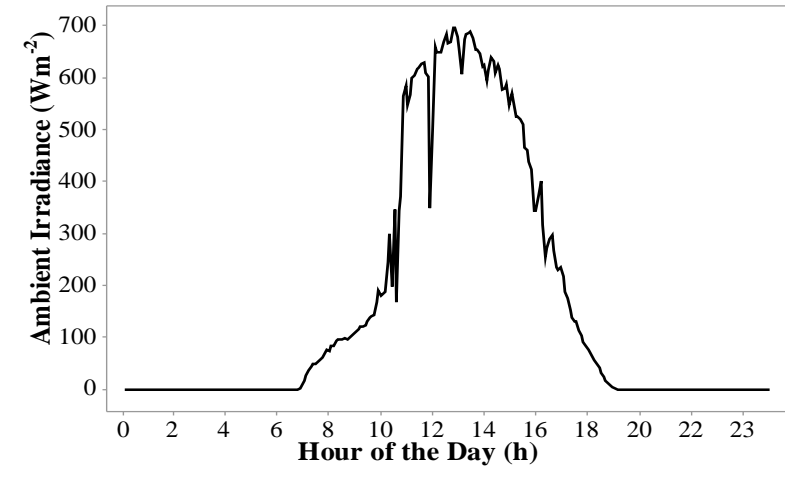

Figure 2. A typical plot of Ambient Irradiance in 24 hours at NNNSS Node.

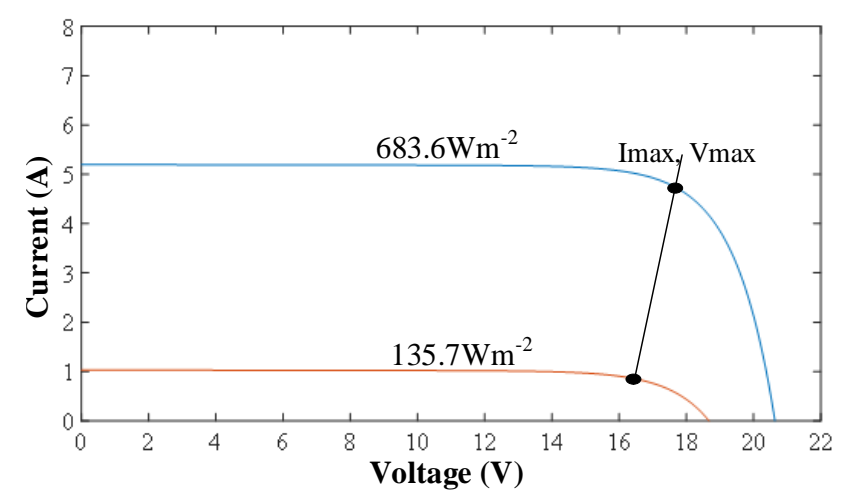

Figure 3. I-V Relationship at NNNSS Node.

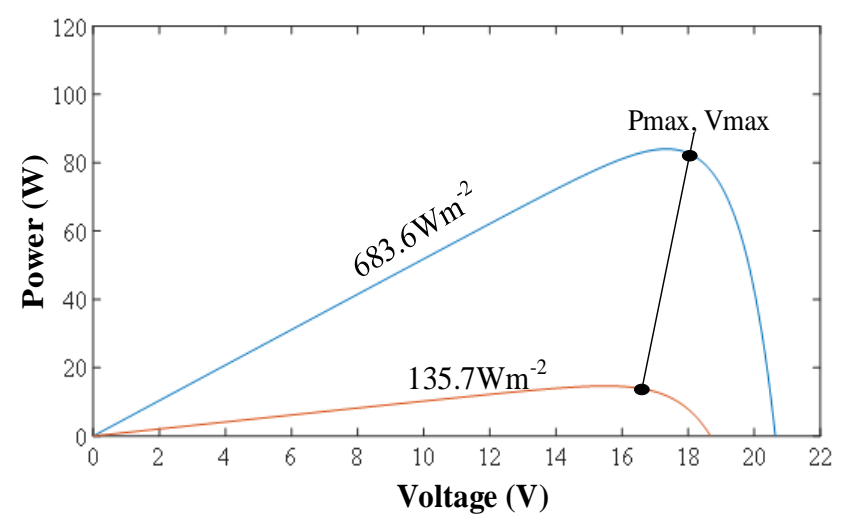

Figure 4. P-V Relationship at NNNSS Node.

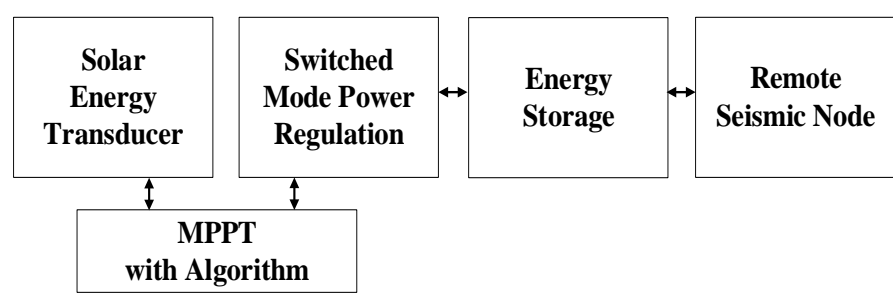

Figure 5. A Block Diagram of Optimizing Solar Energy Harvesting System.
There are several techniques to transduce ambient energy to electrical energy; Radio Frequency (RF) energy radiates in all directions by GSM base and tower stations, Global Navigation of Satellite System (GNSS), Satellite, radar stations, and so many more. This unused ambient energy is constrained with terrain, the number of consumers, and transmission power, so the technique requires a super optimal rectenna to deliver practical power for remote nodes [8] [9]. It is implemented at remote nodes where power consumption is extremely low, the duty cycle is short [10], and outputs are in alternating current(AC). Vibrations can equally be converted into electrical energy by a piezoelectric transducer. Considerate electrical energy is feasible when the vibration transducer is excited with oscillations and a range of lower frequency vibration from 42 to $103 \mathrm{~Hz}$ [10] [11]. The output of a vibration energy transducer is equally in AC. Energy from wind sources depends on direction and change of its speed due to vegetation or topology of the ambient environment, but it requires a considerable energy transducer to convert wind to DC voltage [8].

The thermoelectric transducer utilizes the Seebeck effect to convert wasted thermal heat in the ambient to electrical energy. However, very low DC voltage and power are delivered [12] [8]. Photovoltaic transducer output is DC voltage, and solar irradiance is sufficiently available, particularly in Africa, but with relatively low efficiency. However, its efficiency is relatively low [13].

There are several MPPT algorithms employed to optimize voltage and current levels to deliver maximum power. Some of them are simple and friendly, while others are complex and difficult to implement. Equally, they vary in voltage or current sensors requirements, convergence speed, range of operation, cost as well as load applications [14] [15]. An artificial neural network, incremental conductance, perturb, and observe (P\&O), fuzzy logic control, fractional open-circuit voltage, and many more MPPTs [16] [17]. The simple and most frequently used algorithm is the P \& O [18] [19].

The main contributions of this study are: (1) identifying the constraints of energy harvesting system at NNNSS node and optimizing the constraints to delivering continuous power, and (2) implementing a simple and cost-effective energy harvesting system at the remote seismic node. The paper is organized as follows; in this section, different energy transducers and MPPT algorithms were examined and compared. Section 2 discusses the components of a solar energy harvesting system. Section 3 discuss, investigate, and presents simulation results of the parameters and subsystems at the case study as well as the proposed design. Section 4 provides the conclusion.

\section{SOLAR ENERGY HARVESTING SYSTEM}

An energy harvesting system consists of a PV module, power converter, and energy bank. The inputs parameters of the PV module vary due to environmental changes. Hence, tracking maximum power is not constant. Employing the MPPT algorithm enables the DC-DC converter to match the impedance across its input and that of the load. The proposed 
International Journal of Engineering Research and Technology. ISSN 0974-3154, Volume 13, Number 9 (2020), pp. 2409-2416

(C) International Research Publication House. https://dx.doi.org/10.37624/IJERT/13.9.2020.2409-2416

design intends to use parameters in the case study, as shown in Table 1.

Table 1. Electrical Parameters at NNNSS Node

\begin{tabular}{|l|l|}
\hline Parameter & Value \\
\hline Maximum $P_{\text {ower, }} P_{\max }$ & $60 \mathrm{~W}^{*} 2$ \\
\hline Voltage at $P_{\max }\left(\mathrm{V}_{\max }\right)$ & $17.1 \mathrm{~V}$ \\
\hline Current at $P_{\max }\left(\mathrm{I}_{\max }\right)$ & $3.5 \mathrm{~A}^{*} 2$ \\
\hline Isc & $3.8 \mathrm{~A}^{*} 2$ \\
\hline Voc & $21.1 \mathrm{~V}$ \\
\hline Node Terminal Voltage/Current & $12 \mathrm{~V} / 0.8 \mathrm{~A}$ \\
\hline
\end{tabular}

\section{DISCUSSION AND RESULTS}

\section{A. PV Module}

Two Solarex MSX 60 Modules connected in parallel with parameters in Table 1, acquired at Nsukka seismic node as a case study. Eqn. 1 to Eqn. 3 were used for the PV module [20] in MATLAB environment with ambient irradiance and temperature levels in the case study obtained from a weather station at Nsukka, operated by Centre for Atmospheric Research Anyigba, Nigeria. Using the case study parameters, current, voltage, and power relationships were simulated and plotted, as shown in Figure 6 to Figure 9 on the MATLAB platform. These imply that, with an optimal MPPT algorithm interfaced with DC-DC converter, the energy harvesting system can deliver the continuous power to the remote seismic node.

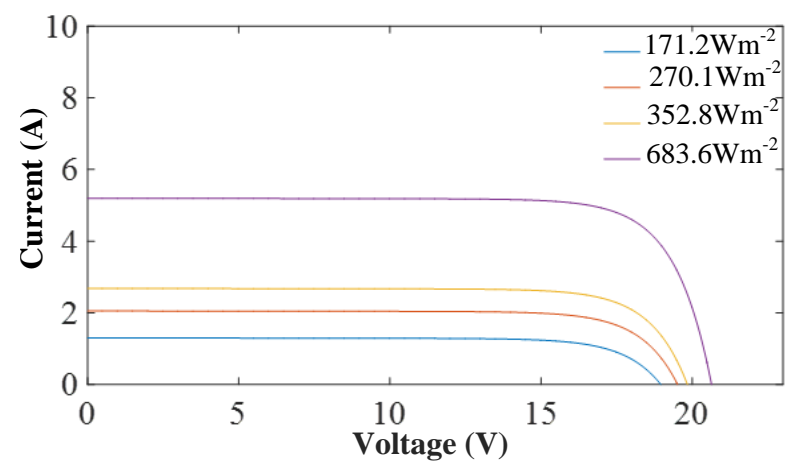

Figure 6. I-V Relationship Plot at the Case Study varying the Ambient Irradiance.

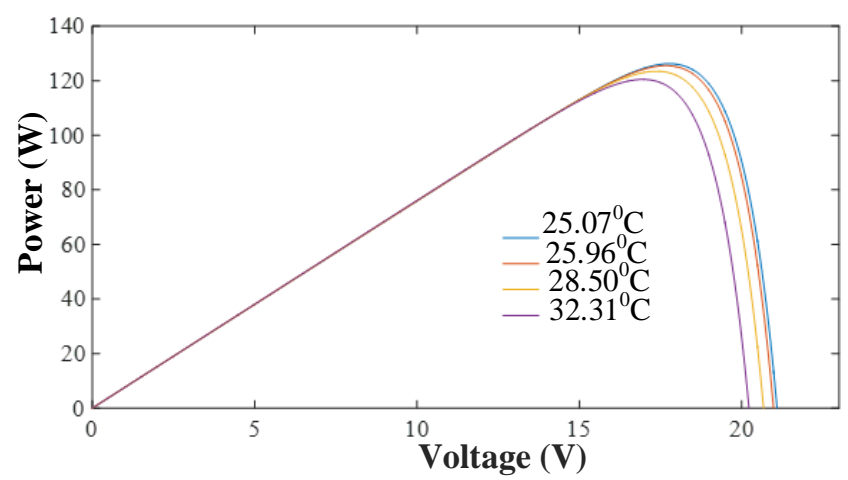

Figure 7. P-V Relationship Plot at the Case Study varying the Ambient Irradiance

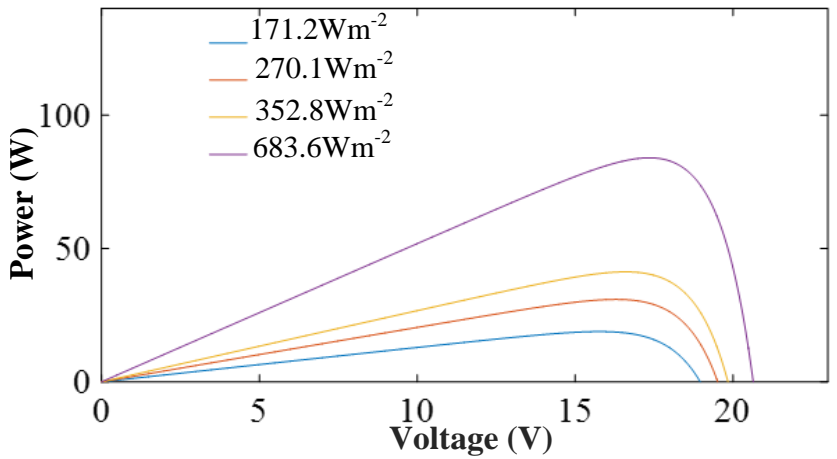

Figure 8. I-V Relationship Plot at the Case Study varying the Ambient Temperature.

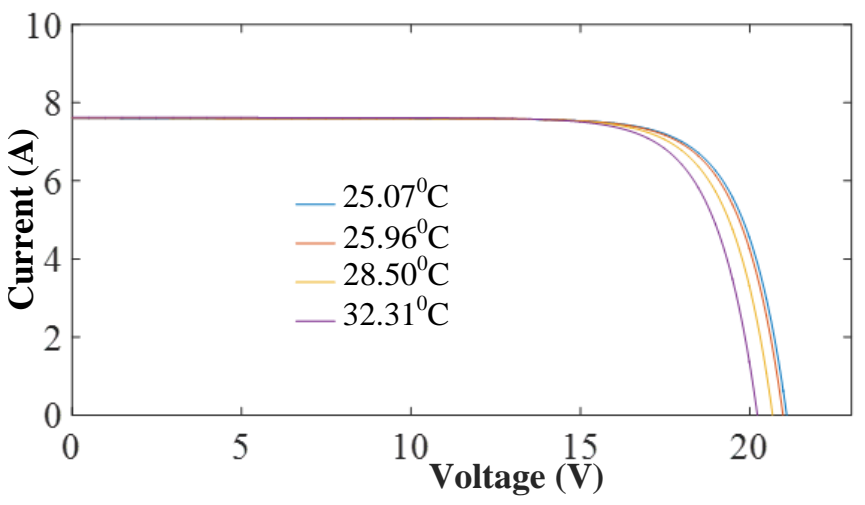

Figure 9. P-V Relationship Plot at the Case Study varying the Ambient Temperature

$V_{O C}=\frac{A * K * T}{q} \ln \left(\frac{I}{I_{\text {sat }}}+1\right)$

$I_{o}=I_{p v}-I_{s a t} *\left(\exp \left[\frac{q *\left(V+\left(I * R_{S}\right)\right)}{K * T * A}\right]-1\right)-\left(\frac{V+\left(I * R_{S}\right)}{R_{S h}}\right)$

$P=V^{*} \mathrm{I}$

$P=\frac{A * K * T}{q} \ln \left(\frac{I}{I_{s a t}}+1\right) *\left[I_{p v}-I_{s a t} *\left(\exp \left[\frac{q *\left(V+\left(I * R_{S}\right)\right)}{K * T * A}\right]\right)-\right.$ $\left.\left(\frac{V+\left(I * R_{S}\right)}{R_{S h}}\right)\right]$

$\mathrm{K}=$ Boltzmann's Constant $\left(1.3806488^{*} 10^{-23}\right.$ joule $\left.^{*} \mathrm{~K}^{-1}\right)$

$\mathrm{q}=$ Charge of the electron $\left(1.602 * 10^{-19}\right)$

I $=$ Terminal Current

IpV $=$ Photocurrent

Isat $=$ Saturated Current

$\mathrm{Voc}=$ Terminal voltage

$\mathrm{R}_{\mathrm{s}}=$ Series Resistance Equivalent Solar Cell Circuit

A $=$ Ideality Factor of the Diode

$\mathrm{R}_{\mathrm{sh}}=$ Shunt Resistance of Equivalent Solar Cell Circuit

$\mathrm{P}=$ Generated Power

To obtain the optimal power outputs as the maximum possible power described by plots in Figure 3 and Figure 4, the most substantial areas of the rectangle fitted under the curves are the respective optimal power outputs, implying; 


$$
\begin{gathered}
\frac{d P}{d V}=\frac{d V_{\text {max }} * I_{\max }}{d V}=0 \\
\left.\frac{d\left\{\frac{A * K * T}{q} \ln \left(\frac{I}{I_{s a t}}+1\right) *\left[I_{p v}-I_{s a t} *\left(\exp \left[\frac{q *\left(V+\left(I * R_{s}\right)\right)}{K * T * A}\right]-1\right)-\left(\frac{V+\left(I * R_{s}\right)}{R_{s h}}\right)\right]\right.}{d V}\right\} \\
\frac{I_{\text {sat }}\left(\exp \left[\frac{q * V}{K * T * A}\right]-1\right)+I_{\text {sat }}\left[\frac{q * V}{K * T} \exp \left(\frac{q * V}{K * T * A}\right)\right]=I_{p v}}{}
\end{gathered}
$$

Approximately, the optimal $\mathrm{I}_{\mathrm{pv}}$ can be defined as:

$$
=I_{\text {sat }} \exp \left(\frac{q V_{\max }}{A * K * T}\right)+\left(\frac{q * V_{\max } * I_{s a t}}{K * T * A}\right) * \exp \frac{q * V_{\max }}{K * T * A}
$$

and,

$$
=I_{\text {sat }} \exp \left(\frac{q * V_{\max }}{A * K * T}\right)\left(1+\frac{q * V_{\max }}{K * T * A}\right)
$$

Relating the $\mathrm{V}_{\max }$ Eqn. 9 to the $\mathrm{V}_{\mathrm{oc}}$ in Eqn. 1, $\mathrm{I}_{\mathrm{pv}}$ can be taken as:

$$
\begin{aligned}
& I_{p v}=I_{s a t} * \exp \left(\frac{q V_{o c}}{A * K * T}\right) \\
& V_{\text {max }}=V_{o c}-\left[\frac{K * T * A}{q} \ln \left(1+\frac{q * V_{\max }}{K * T * A}\right)\right]
\end{aligned}
$$

Assuming the Ideality Factor of the Diode, $A=1$

$$
\frac{K * T}{q}=0.02586 \mathrm{~V}
$$

and

$$
0.0258 \mathrm{~V} \ln (1+38.669)=0.0949 \mathrm{~V}
$$

By considering that $\ln (\mathrm{x})$ is growing slowing with $\mathrm{x}$ [21], it can be equally assumed that

$$
\ln \left(1+\frac{q * V_{\max }}{K * T}\right)=\ln \left(1+\frac{q * V_{o c}}{K * T}\right)
$$

So therefore, optimal Voltage, $\mathrm{V}_{\max }$ can be approximated as:

$$
V_{\text {max }}=V_{O C}-\frac{K * T}{q} \ln \left(1+\frac{q V_{o c}}{K T}\right)
$$

Also, the optimal current, $I_{\max }$ can be approximated as:

$$
I_{\max }=I_{s a t}\left[\exp \left(\frac{q * V_{o c}}{K * T}\right)\right]-I_{P V}
$$


Based on the analytical method to determine the accurate $\mathrm{V}_{\max }$ and $\mathrm{I}_{\max }$, multiple measurements of different voltage variations are required, implying it very difficult to track the operating point on the I-V plot. As discussed earlier, several MPPT exist. The likelihood of an algorithm to track the voltage value corresponding to the maximum power makes it an optimal technique to deliver optimal power. Perturb and Observe (P \& O) delivers optimal results in this paper. The algorithm flowchart shown in Figure 10, perturbs the voltage levels by adjusting the duty cycle, D, towards an operating point where an optimal power is attained in PSIM.

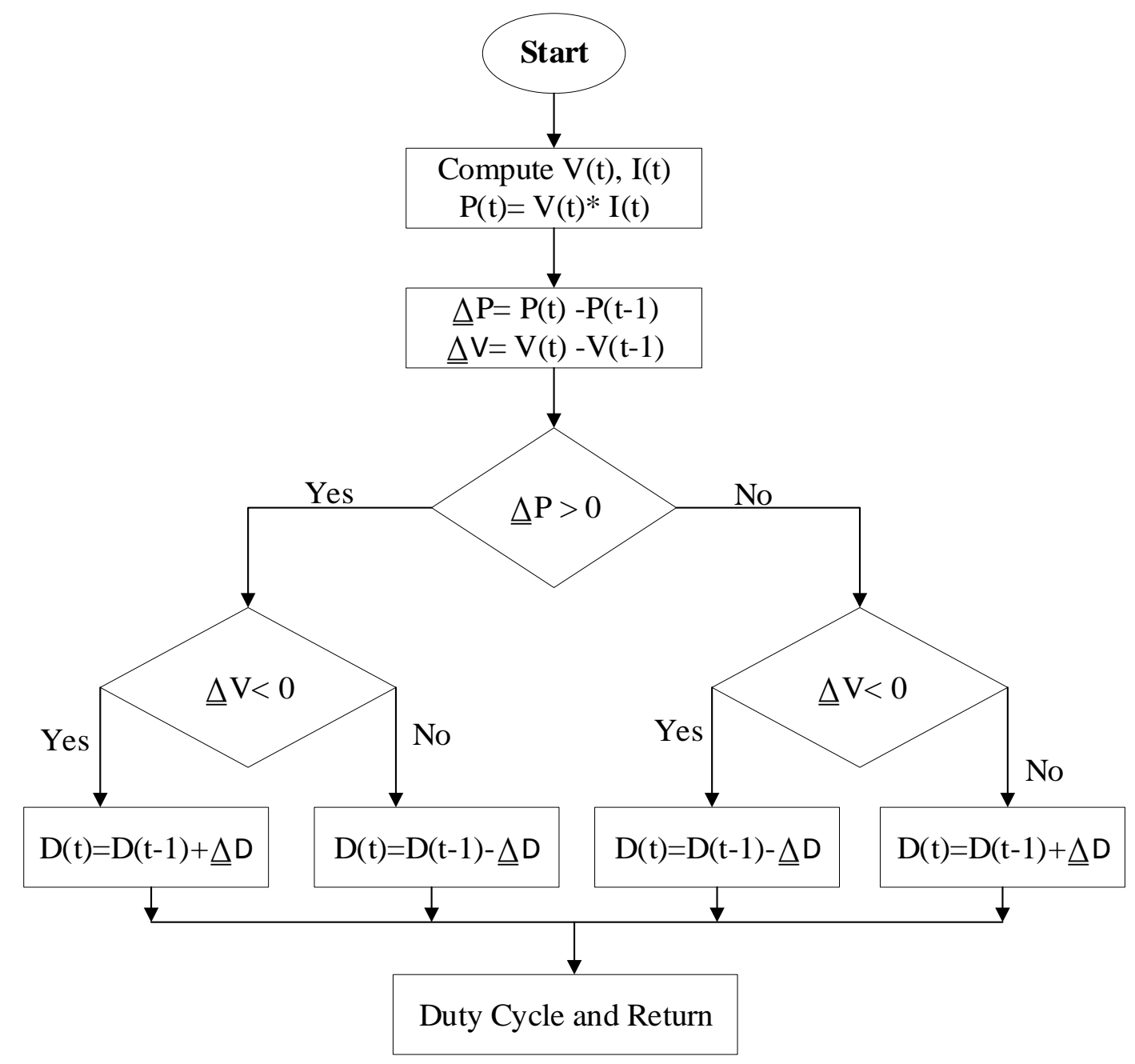

Figure 10. Perturb and Observe Algorithm Flowchart

\section{B. Modelling DC-DC Converter}

Buck converter is implemented based on the case study parameters in Table 1 for the input parameters, and Table 2 for the main converter. Two PV modules are connected in parallel and simulated in PSIM, with irradiance and temperature levels of $683 \mathrm{Wm}^{-2}$ and $29^{\circ} \mathrm{C}$, respectively. Traditionally, buck converter generates ripples at the output to introduce noise and reduce efficiency. The inductor and capacitor in Figure 11(b) perform the work of the low-pass filter, as demonstrated in Figure 12 and Figure 13, the inductance limits the ripple in the output current. At the same time, the capacitance suppresses ripples across output voltage. This optimally improves the dynamic response and maintain $12 \mathrm{VDC}$ at the output, as shown in the figures with increased efficiency.
Table 2. Simulation Parameters for the Buck Converter

\begin{tabular}{|l|l|}
\hline Parameter & Value \\
\hline Inductor & $750 \mathrm{uH}$ \\
\hline Output Capacitor & $380 \mathrm{uF}$ \\
\hline Duty Cycle & 0.637 \\
\hline Switching Frequency & $5 \mathrm{KHz}$ \\
\hline
\end{tabular}


International Journal of Engineering Research and Technology. ISSN 0974-3154, Volume 13, Number 9 (2020), pp. 2409-2416

(C) International Research Publication House. https://dx.doi.org/10.37624/IJERT/13.9.2020.2409-2416

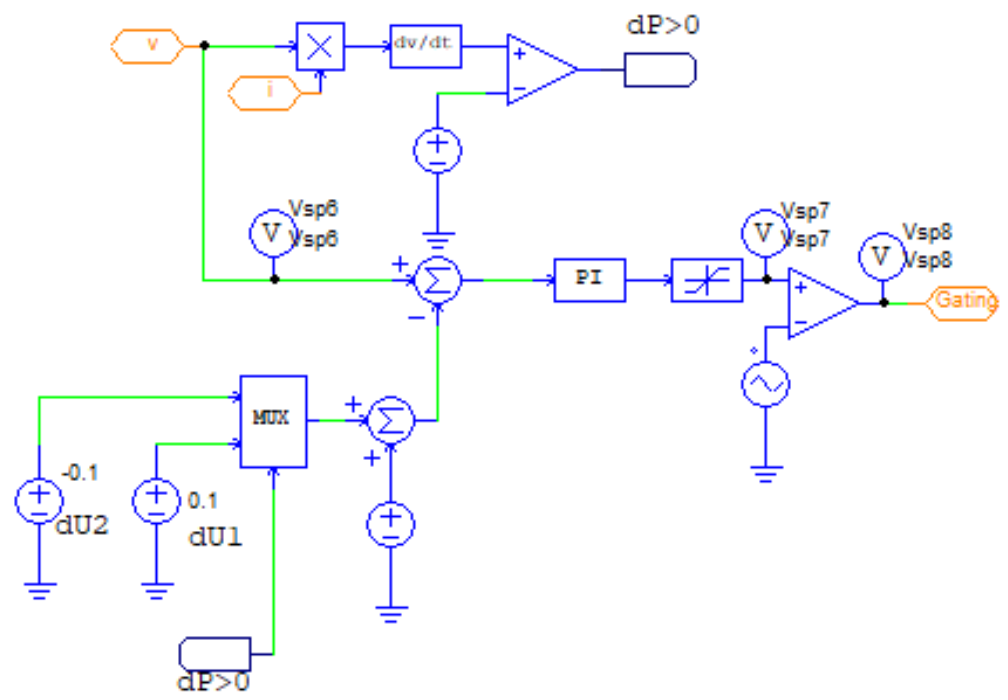

(a)

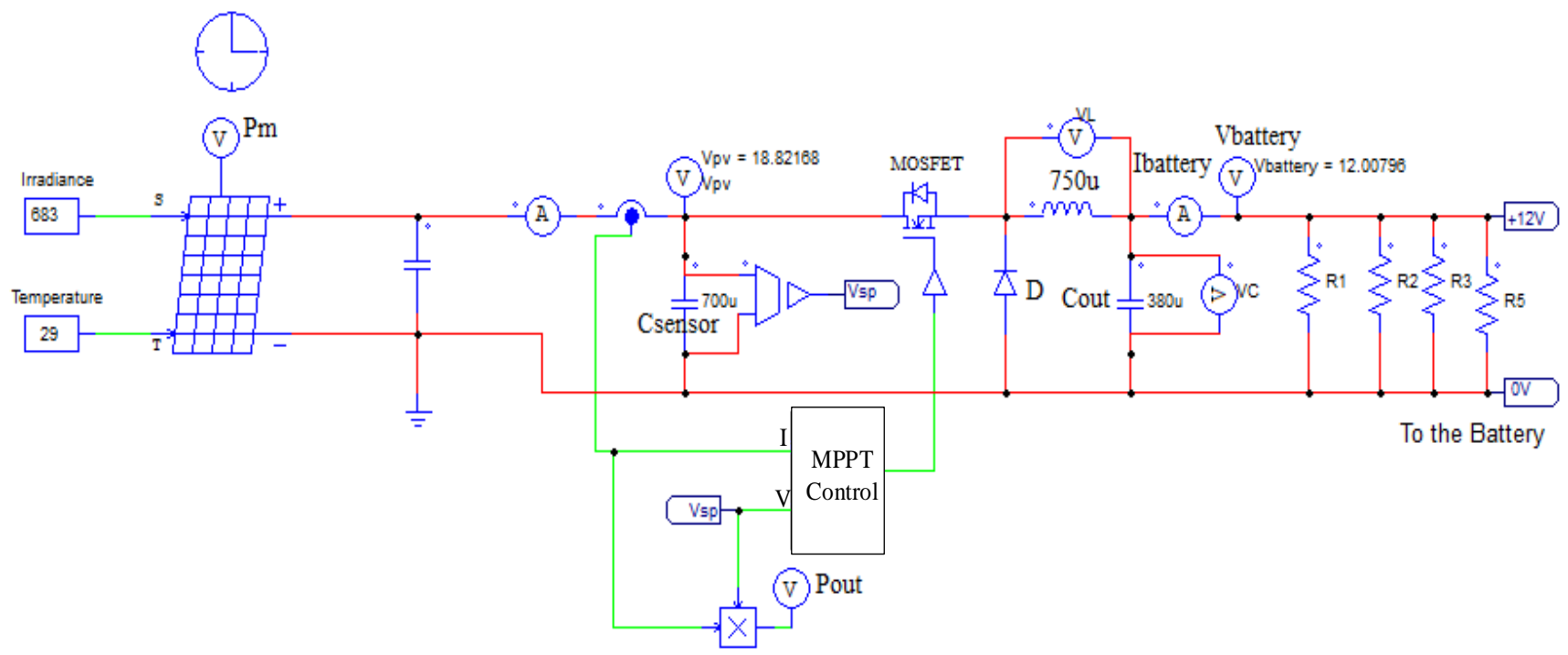

(b)

Figure 11. The Proposed Solar Energy Harvesting System of (a) MPPT Circuit and (b) Buck Converter

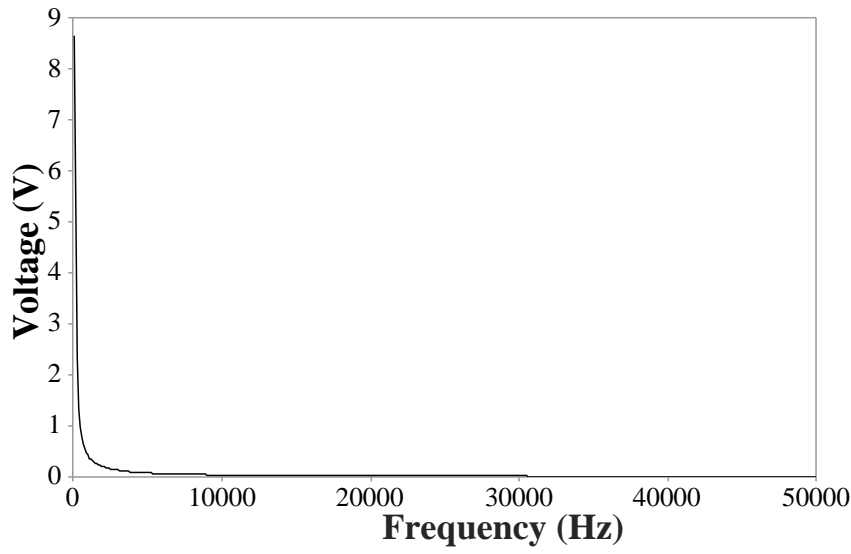

Figure 12. The Plot of the Voltage Ripples across the Load

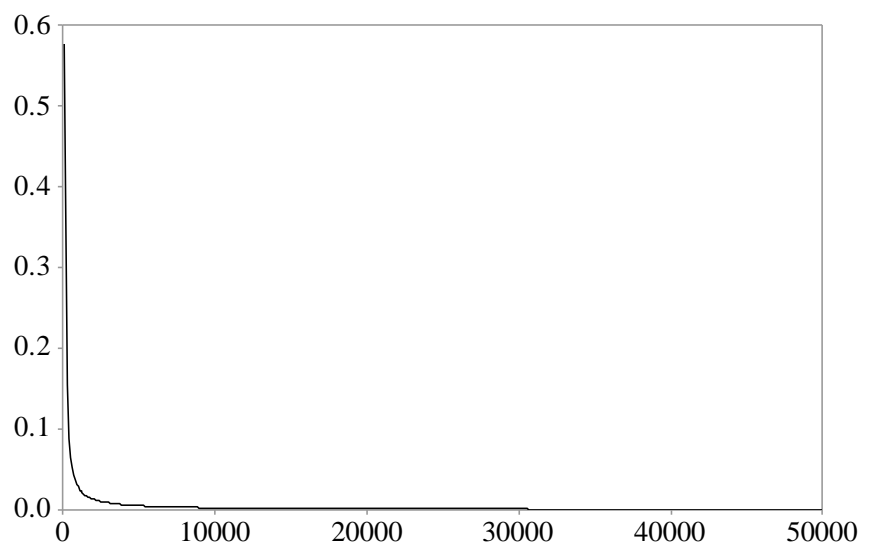

Figure 13. The Plot of Current Ripples at the Load 


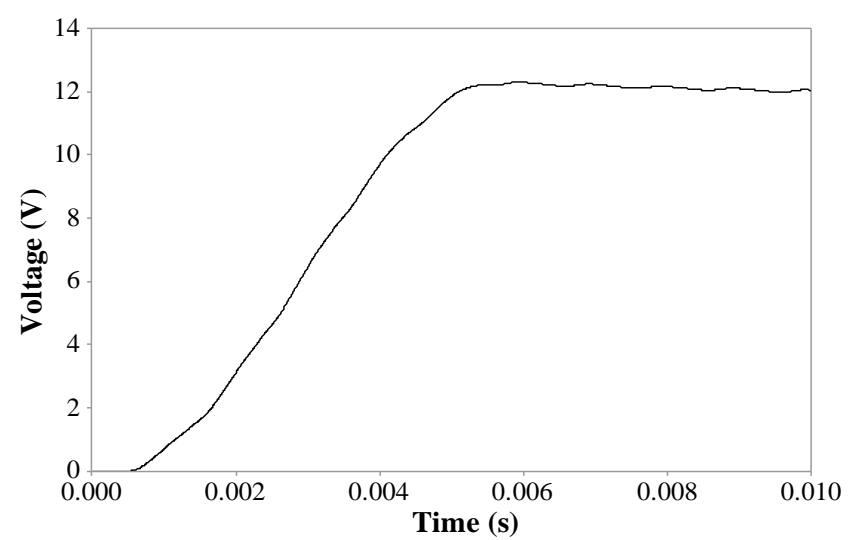

Figure 14. The Plot of Output Voltage across the load

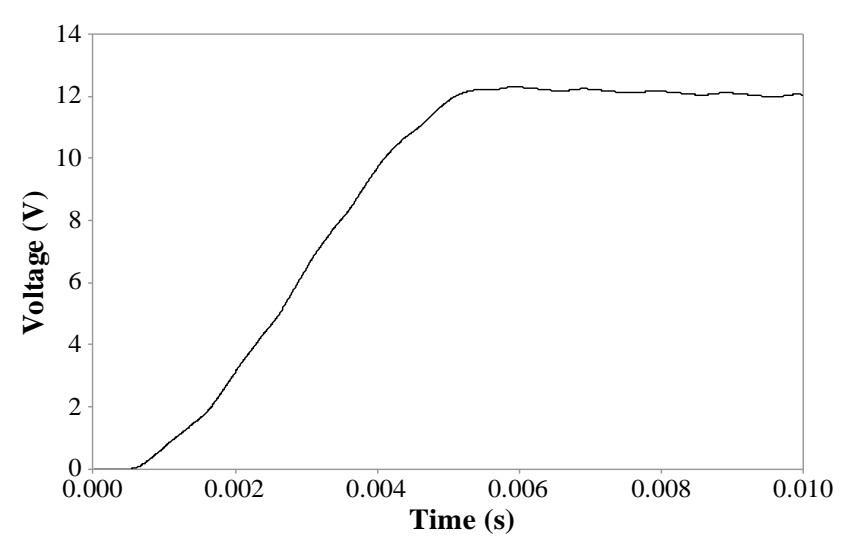

Figure 15. The Plot of Voltage across the Output Capacitor

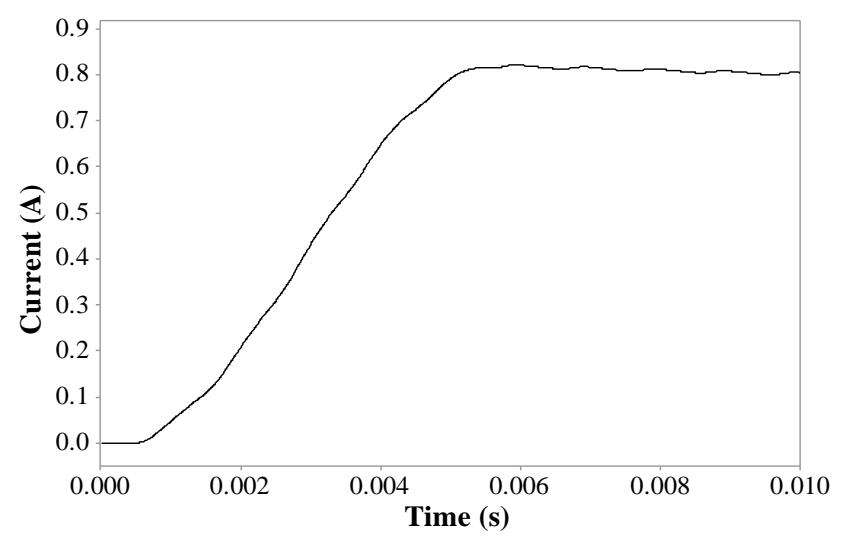

Figure 16. The Plot of Current drawn by the node

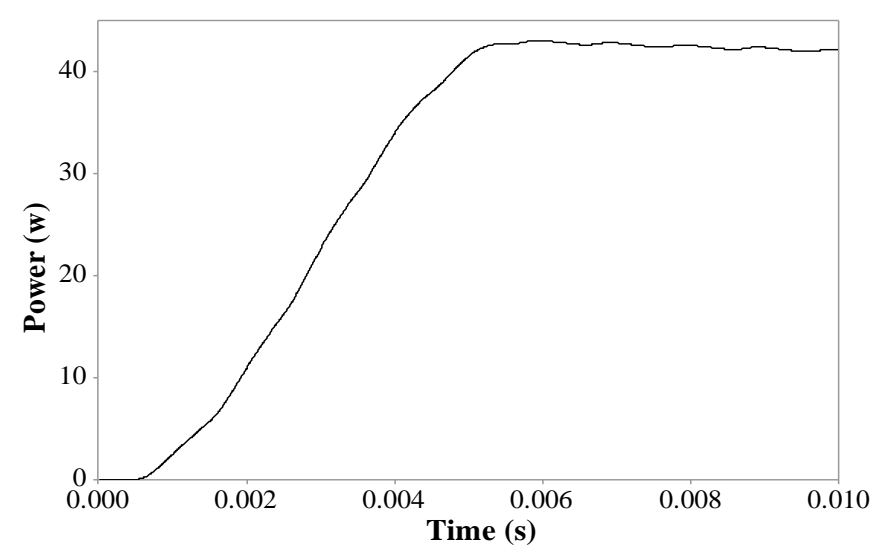

Figure 17. The Plot of Generated Power with MPPT control.

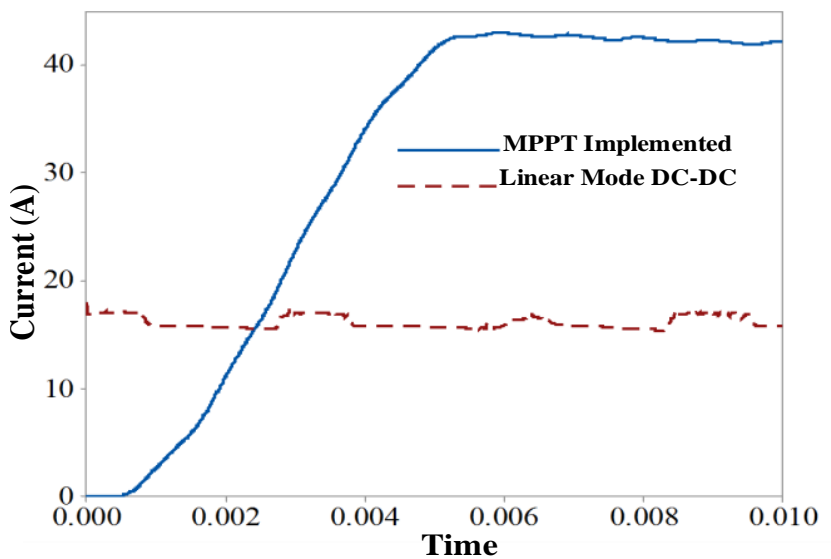

Figure 18. The Comparison Plot of Generated Power with MPPT control and Existing Energy Harvesting System.

The power rating of the combined PV module is $120 \mathrm{Watts}$ at the node to energize $10 \mathrm{~W}$ seismic instrumentation and charge a lead-acid battery simultaneously. The existing energy harvesting system has been unable to sustain the remote seismic node constantly, and it fails frequently. The proposed design would be able to supply twice the power to the load and the battery to enable continuous power supply.

\section{CONCLUSIONS}

This DC-DC converter with the perturb and observe algorithm in the energy harvesting system can simply deliver maximum possible power by adjusting its duty cycle at any change in ambient irradiance. Although the PV module has relatively low efficiency, optimal voltage and power were produced with low ripples and delivered an additional $80 \%$ of the existing electrical energy.

\section{ACKNOWLEDGMENTS}

The authors wish to acknowledge the following bodies for their financial support, scientific data, and cooperation towards this article:

ORDI of the Botswana International University of Science and Technology, Palapye, Botswana under Grant R0065,

Centre for Geodesy and Geodynamics, Nigeria,

Centre for Atmospheric Research, Anyigba, Nigeria

\section{REFERENCES}

[1] A. U. Kadiri, T. A. Yakubu, U. O. Akpan, D. Duncan and S. U. Usifoh, "Towards an integrated seismic hazard monitoring in Nigeria using geophysical and geodetic techniques," International Journal of the Physical Sciences, vol. 6, no. 28, pp. 6385-6393, 2011.

[2] O. U. Akpan and T. A. Yakubu, "A review of earthquake occurrences and observations in Nigeria," Earthquake Science, Volume 23, Issue 3, pp.289-294, vol. 23, no. 3, 
p. $289-294,2010$

[3] J. O. Oluwafemi, O. M. Ofuyatan, A. N. Ede, S. O. Oyebisi, I. I. Akinwumi and K. 0. Babaremu, "Review of Earthquakes in Nigeria: An Understudied Area," International Journal of Civil Engineering and Technology (IJCIET), vol. 9, no. 8, p. 1023-1033, 2018.

[4] "Alternative Approaches to Modeling Epistemic Uncertainty in Ground Motions in Probabilistic SeismicHazard Analysis," Seismological Research Letters, 2014.

[5] N. Yılmaz and M. S. Yücemen, "Sensitivity of seismic hazard results to alternative seismic source and magnitude-recurrence models: a case study for Jordan," Geodinamica Acta, vol. 27, no. 2-3, pp. 189-202, 2014.

[6] M. E. Kiziroglou and E. Yeatman, "Kinetic, thermoelectric and solar energy harvesting technologies for smart textiles," Sciebce Direct, vol. 2013, no. 2013, pp. 306-328, 2012.

[7] J. Havskov and G. Alguacil, Instrumentation in Earthquake Seismology, Springer: London, 2016.

[8] S. Sojan and R. K. Kulkarni, "A Comprehensive Review of Energy Harvesting Techniquesandits Potential Applications," International Journal of Computer Applications, vol. 139, no. 3, pp. 14-19, 2016.

[9] G. P. Ramesh and A. Rajan, "Microstrip Antenna Designs for RF Energy Harvesting," in International Conference on Communication and Signal Processing, Apri[ 3-5, 2014, India, India, 2014.

[10] K. Singhand and S. Moh, "A Comparative Surveyof Energy Harvesting Techniques for Wireless Sensor Networks," Advanced Science and Technology Letters, vol. 142, no. 2016, pp. 28-33, 2016.

[11] Y. Yoon, W. Park, K. H. H. Li, Y. Q. Ng, Q. and Y. Song, "A Study of Piezoelectric Harvesters for LowLevelVibrations in Wireless Sensor Networks," INTERNATIONAL JOURNAL OF PRECISION ENGINEERING AND MANUFACTURING, vol. 14, no. 7, pp. 1257-1262, 2013.

[12] F. Yildiz and K. Coogler, "Low power energy harvesting with a thermoelectric generator through an air conditioning condenser," in 121ST ASEE Annual Conference \& Exposition, Indianapolis, 2014.

[13] L. Idoko, O. Anaya-Lara and A. MacDonald, "Enhancing PV modules efficiency and power output using," Elsevier , vol. 4, no. 2018, pp. 357-369, 2018.

[14] R. Faranda, L. S. and V. Maugeri., "MPPT techniques for PV Systems: energetic and cost comparison," in IEEE ConferencePublications, Pittsburgh, 2008.

[15] T. Esram and P. L. Chapman, "Comparison of photovoltaic array maximum power point tracking techniques," IEEETrans. Energy Convers.22, , vol. 22, no. 2007, p. 439-449, 2007.

[16] M. A. G. de Brito, L. P. Sampaio, G. Luigi, G. A. e Melo and C. A. Canesin, "Comparative analysis of MPPT techniques," in International Conference on Clean Electrical Power (ICCEP), 2011.
[17] S. Mekhilef, A. Safari, W. E. S. Mustaffa, R. Saidur, R. Omar and A. A. Younis, "Solar energy in Malaysia: Current state and prospects," Renewable Sustainable Energy, vol. 16, no. 1, p. 386-396, 2012.

[18] M. A. Elgendy, B. Zahawi and D. J. Atkinson, "Assessment of Perturb and Observe MPPTAlgorithm Implementation Techniquesfor PV Pumping Applications," IEEE TRANSACTIONS ON SUSTAINABLE ENERGY,, vol. 3, no. 1, pp. 21 - 33, 2012.

[19] M. A. Elgendy, B. Zahawi and D. J. Atkinson, "EVALUATION OF PERTURB AND OBSERVE MPPT ALGORITHM IMPLEMENTATION TECHNIQUES," in 6th IET International Conference on Power Electronics, Machines and Drives (PEMD 2012), Bristol, 2012.

[20] Earthsscan, "THE BEHAVIOUR OF SOLAR CELLS," www.knovel.com, 2007.

[21] http://www.ee.sc.edu/personal/faculty/simin/ELCT566/ 21\%20Solar\%20Cells\%20II.pdf. 